research staff on the activities of universities and medical schools throughout the country. Clearly it is essential to establish a balance between the M.R.C. and the universities that will not be harmful to either in the competition for scarce talent and finance. The council hąs been wise and generous in assisting research in the universities and medical schools, so that a tradition of fruitful interchange has grown up that has brought great benefits to both. But if too high a proportion of men and women in teaching posts who show promise of research ability are attracted into whole-time research in the council's units some anxiety might be felt for the future of teaching in the medical schools. The teaching of future generations and the carrying out of research should go hand in hand, and if the M.R.C. proves attractive to research workers it is up to the universities to offer counter-attractions. A sense of proportion is surely important here, and the fact that, like the University Grants Committee, the Medical Research Council is composed largely of academic members gives considerable assurance that the needs of the universities will not suffer by default.

Under the wise guidance of Sir Harold Himsworth the expansion of the Medical Research Council's activities and the development of its administrative machinery have proceeded gradually and effectively. A break in the curve seems to be both unnecessary and unlikely. All will wish the new secretary, Dr. J. B. Gray, an enjoyable and fruitful tenure of his most responsible post. But he will certainly find that no one with such responsibility can please everybody all the time.

\section{Cardiomyopathy and Pregnancy}

Unexpected, unexplained heart failure in the puerperium or late pregnancy has been reported sporadically for more than a century. ${ }^{1-11}$ In current jargon the syndrome is now usually dubbed postpartum cardiomyopathy. Individual experience is limited by the racity of the condition, and incomplete "reviews of the literature" abound. Nevertheless, there is a characteristic picture exemplified in the patient described by Dr. I. M. Ledingham and his colleagues in Glasgow at page 285. Heart failure develops acutely. Angina, transient hypertension, and arrhythmias are common, and sometimes the presentation is with systemic or pulmonary embolism. The onset is more often post-partum than in late pregnancy and almost never earlier than the last trimester. The outcome varies; there may be rapid death, a chronic cardiac disorder, or complete recovery. At necropsy all that is usually found is evidence of the heart failure, and indeed in fulminatingly acute cases the weight of the heart may be normal, thereby excluding pre-existing heart disease. Myocardial degeneration and necrosis found on histological examination does not differ except in magnitude from that seen in the more indolent cardiomyopathies unassociated with pregnancy.

The existence of a specific cardiomyopathy of pregnancy has been disputed by those who suggest that the raised blood volume and cardiac output of pregnancy may simply bring out a previously silent cardiac disorder. ${ }^{10}$ The condition is rare in affluent communities, and this has led to the suggestion that marginal malnutrition and the metabolic demands of pregnancy may render the heart more susceptible both to infection and to drug toxicity. W. R. Meadows ${ }^{7}$ and others who have studied many cases in economically poor communities share both the largest experience and the belief that this is a specific form of heart disease. These workers stress that the cardiomyopathy tends to recur and progress in subsequent pregnancies, and that when heart failure develops for the first time in the puerperium cardiomyopathy is the likely cause.

Cardiomyopathies vary widely, but because so little is known about them the term cardiomyopathy is often used in lieu of a specific diagnosis. Cardiomyopathy may be associated with general disorders such as haemochromatosis, amyloid, or polyarteritis and sometimes follows infections, as in Chagas's disease due to trypanosomiasis and Coxsackie B virus myocarditis. Much more commonly the cause is completely unknown, the heart dilates, and heart failure remains the sole feature: so-called congestive cardiomyopathy. In older patients the disorder may be wrongly attributed to coronary artery disease. In the young, in whom heart failure is more unexpected, the cardiac dysfunction is sometimes missed until an advanced stage of decompensation has been reached, interim diagnoses of respiratory or neurotic disease being preferred. Though rare, a post-partum cardiomyopathy accounts for several maternal deaths each year in Britain. Before the diagnosis is made it is imperative that hypertensive heart disease, heart failure associated with "toxaemia of pregnancy," nutritional cardiomyopathy, pericardial disease, and pulmonary embolism should be excluded. The rare possibilities-cardiac tumour, silent mitral stenosis, precocious coronary thrombosis, and obliterative pulmonary hypertension -must also be considered.

Fortunately, much more common in pregnancy are patients with a diametrically different type of disorder of heart muscle which has a better outlook both during pregnancy and in the long term. Hypertrophic obstructive cardiomyopathy has become widely recognized through intensive study in the last decade. The more typical clinical features of this often familial condition are now well known, but the disorder appears in many disguises and is a great mimic. ${ }^{12}$ Most affected patients are young adults when the diagnosis is made. They tend to be of good physique, heart failure is not a feature, and symptoms are usually not demanding. Not surprisingly, therefore; hypertrophic obstructive cardiomyopathy is now being seen in pregnancy, and the obstetric experience in nine patients is described this week by Dr. Gillian Turner and her colleagues at page 281.

The combination of a powerful rapidly emptying left ventricle with late systolic obstruction to further ejection and mitral regurgitation gives rise to jerky arterial pulses, raised venous pressures, gallop sounds, and mid or late systolic murmurs. Such signs are present to a lesser extent in pregnant

1 Meigs, C. D., Females and their Diseases, 1848, p. 501, Lea and Blanchard. Philadelphia quoted by Gilchrist.

Virchow, R., Sitzung der Berliner Geburtshuelficher Gesellschaft, 1870 , quoted by Gouley.

${ }^{3}$ Gouley, B. A., McMillan, T. M., and Bellet, S., Amer. F. med. Sci., 1937, 194, 185.

- Brigden, W., Lancet, 1957, 2, 1179.

5 Rosen, S. M., Brit. med. Ұ., 1959, 2, 5.

Benchimol, A. B., Carneiro, R. D., and Schlesinger, P., Brit. Heart \}., $1959,21,89$

Meadows, W. R., Amer. F. Cardiol., 1960, 6, 788.

Walsh, J. J., Burch, G. E., Black, W. C., Ferrans, V. J., and Hibbs, R. G., Circulation, 1965, 32, 19.

9 Faruque, A. A., Brit. Heart $7 .$, 1965, 27, 139.

Brown, A. K., Doukas, N., Riding, W. D., and Wyn Jones, B.,
Brit. Heart f., 1967, 29, 387 .

Perrine, R. P., Trans. Roy. Soc. Tropical Med. and Hyg., 1967, 61, 834.

12 Brit. med. 7., 1966, 1, 2.

13 Gilchrist, A. R., Brit. med. 7., 1963, 1, 209.

1. Watson, H., Emslie-Smith, D., Herring, J., and Hill, I. G. W., Lancet, $1960,2,523$. 
patients with normal hearts, and diagnosis may not be easy. Less flamboyant cases with a hypertrophied myocardium but little obstruction or mitral regurgitation except under stress may have no convincing signs of heart disease. Others may have as their only feature angina atiributable to increased metabolic demands of the thickened myocardium. Yet others have an abnormal electrocardiogram but no angina.

A. R. Gilchrist ${ }^{13}$ has distinguished a group of young women with angina and tachycardia but no heart failure, in whom the prognosis was good even though pain and electrocardiographic abnormalities persisted after pregnancy. It seems very likely that some of these may have been examples of hypertrophic obstructive cardiomyopathy. But coronary thrombosis can occur in pregnancy, ${ }^{14}$ and conversely angina with focal infarction patterns on the electrocardiogram has been seen in patients with congestive cardiomyopathy in whom the coronary arteries are subsequently proved to be normal.

Sudden death is a hazard of hypertrophic obstructive cardiomyopathy. When the diagnosis was made in pregnant women it led the Hammersmith group to intensive prophylactic therapy based on theoretical considerations. Greater experience was more reassuring; but despite this favourable experience in the management of patients with this disorder precautions relevant to the known haemodynamic abnormalities seem sensible.

\section{Exchange Transfusion in Fulminant Hepatitis}

Reports that patients in hepatic coma due to fulminant hepatitis had recovered after exchange transfusion raised hopes that a simple method might now be available for the treatment of a condition with a previous mortality rate or $90 \% .^{12}$ S. J. Saunders, ${ }^{3}$ from Cape Town, whose group was largely responsible for introducing this technique, continues to get good results. Eleven out of 22 patients have recovered completely and six are alive and well. Many of the patients were children, and experience in Great Britain with adults is less encouraging. Though temporary improvement in consciousness has occurred, most patients have died, and the histological appearances of the liver post mortem have been such as to suggest that cirrhosis would inevitably have developed. ${ }^{4}$

A recent study also questioned whether the mortality of this condition is as high as was suggested. M. A. Davis and colleagues $^{5}$ found that six out of 16 patients with acute viral hepatitis and hepatic coma admitted to Los Angeles County Hospital over an 18-month period recovered on conservative treatment. The three patients treated by exchange transfusion died. At the time of coma there were no distinguishing clinical features or laboratory tests that allowed prediction of survival. However, the Fulminant Hepatic Failure Surveillance Study, which has collected data from many centres throughout the world, describes in a recent progress report ${ }^{6}$ a $19 \%$ survival rate among 94 cases treated by exchange transfusion, dialysis, or other extracorporeal procedures compared with $10.4 \%$ in 48 patients treated conservatively.

The latter survey has also renewed interest in halothane as a cause of massive hepatic necrosis. In an analysis of 54 cases of acute hepatic failure 28 were of presumed viral hepatitis, but 21 had undergone operation under general anaesthesia within eight weeks of the onset. ${ }^{7}$ Sixteen of these had had halothane, 12 on more than one occasion. Unexplained fever shortly after the next to last anaesthetic had occurred in 8 of these 12 patients, and the dangęrs of multiple exposure to halothane after prior unexplained fever or signs of liver impairment must be stressed.

The beneficial effects of exchange transfusion may be due to removal of the toxic substances causing hepatic coma or to the provision of substances in the blood given, such as clotting factors or even factors concerned in hepatic regeneration. $^{8}$ The beneficial effects of exchange transfusion in dogs with fulminant canine hepatitis are due to the presence of specific neutralizing antibodies in the donor blood. ${ }^{910}$ However, in other experimental studies, in which massive hepatic necrosis was induced in monkeys by the intraportal injection of carbon tetrachloride, exchange transfusion was also effective. At necropsy all showed massive necrosis, but in those treated by exchange transfusion there was undoubted evidence of hepatic regeneration. ${ }^{11}$

Fortunately, fulminant hepatic failure, whether due to infectious hepatitis or following anaesthesia or monoamine oxidase inhibitors, is rare, and much of this argument may seem academic to the physician faced with the occasional case. The evidence, on balance, is that exchange transfusion is beneficial rather than harmful. But at what stage should it be tried and how frequently should it be performed? Experience of dialysis in renal failure suggests that exchange transfusion should be performed early rather than late, though this means that some patients will be treated who would have recovered spontaneously. If there is no improvement within 24 hours of starting neomycin, glucose infusion, emptying of the bowel, and corticosteroid therapy exchange transfusion should be tried. It should be noted here, however, that the value of corticosteroids ${ }^{12}$ has not been established in a controlled trial. If some lightening in consciousness, however temporary, is observed then further daily exchanges of the patient's estimated blood volume (usually $3-4$ 1.) are indicated. If there is no significant improvement after three daily exchanges the patient is unlikely to recover, though it is difficult at present to give exact guidance. Various technical procedures have been recommended for the transfusion, but it can be done, though slowly, by venous catheters only;

\footnotetext{
Trey, C., Burns, D. G., and Saunders, S. J., New Engl. f. Med., 1966, 274, 473.

2 Berger, R. L., Liversage, R. M., Chalmers, T. C., Graham, J. H., McGoldrick, D. M., and Stohlman, F., New Engl. f. Med., 1966, 274, 497.

s Saunders, S. J., in The Liver, Proceedings of the 19th Symposium Saunders, S. J., in The Liver, Proceedings of the 19th Symposium
of the Colston Research Soc., edited by A. E. A. Read, 1967.

London.
Jones, E. A., Clain, D., Clink, H. M., MacGillivray, M., and Sherlock, S., Lancet, 1967, 2, 169.

5 Davis, M. A., Peters, R. L., Redeker, A. G., and Reynolds, T. B., New Engl. F. Med., 1968, 278, 1248.

6 New Engl. f. Med., 1968, 278, 1287.

Trey, C., Lipworth, L., Chalmers, T. C., and Davidson, C. S., Trey, C., Lipworth, L., 54, 171 .

8 Williams, R., and Toghill, P. J., Postgrad. med. 7., 1968, 44, 173.

- Morris, T. Q., Gocke, D. J., and Sardi, G. F., f. clin. Invest., 1967, 46, 1098.

10 Preisig, R., Bonifas, V., and Cottier, H., Schweiz. med. Wschr., 1967, 97, 1373.

1 Trey, C., Garcia, F., and King, W., Gastroenterology, 1968, 54, 171.

12 Katz, R., Velasco, M., Klinger, J., and Alessandri, H., GastroenteroKatz, R., Velasco, M.

${ }_{3}$ Lederman, R. J., Davis, F. B., and Davis, P. J., Ann. intern. Med., 1968, 68, 830 .

it Sabin, S., and Merritt, J. A., Ann. intern. Med., 1968, 68, 1.

15 Watts, J. McK., Douglas, M. C., Dudley, H. A. F., Gurr, F. W., and Owen, J. A., Brit. med. F., 1967, 2, 341.

- Burnell, J. M., et al., New Engl. f. Med., 1967, 276, 935.
} 